\title{
Dual-band Metamaterial Filtenna for WiMAX Application
}

\author{
Nuradlina Azman, Mohd Fairus Mohd Yusoff* and Muhammad Akram Mohd Sobri \\ School of Electrical Engineering, Faculty of Engineering, Universiti Teknologi Malaysia, 81310 UTM Skudai, Johor, \\ Malaysia.
}

"Corresponding author: fairus@ @ fke.utm.my

\begin{abstract}
Filter and antenna are the most important components in transmission and receiving signal in wireless communication system. The combination of a filter and antenna is call as filtenna. In this paper, a metamaterial band-stop filter is combine with a multiband antenna to produce a dual-band metamaterial filtenna. The purpose of combining both in one structure is to have a compact size and to reduce the transmission line losses. In addition, by implementing the metamaterial structure in the filter design, it can help to increase the overall filtenna performances. All the designs is simulated using CST Microwave Studio software. The performances of the dual-band metamaterial filtenna are analysed based on its S-parameter response and radiation patterns. The simulation results shows that the filtenna has operates at $2.6 \mathrm{GHz}$ and $5.2 \mathrm{GHz}$, which is mostly suitable for WiMAX application.
\end{abstract}

Keywords: Band-stop filter, complemantary split-ring resonator (CSRR), filtenna, metamaterial, multiband antenna.

Article History: received 2 August 2018; accepted 10 April 2019; published 25 April 2019.

(C) 2019 Penerbit UTM Press. All rights reserved

\section{INTRODUCTION}

In recent years, the challenges in developing the modern wireless communication have led to the design of communication devices with the characteristics of compact size, low cost and easy to be fabricated [1]. Filter and antenna are the most important components in transmission and receiving signal in wireless communication system. Recently, the combination of a filter and antenna is call as filtenna have been paid more attention. The purpose of combining both in one structure is to have a compact size and to reduce the transmission line losses.

Thus, filters are one of the most significant components that have a major role in transmitting and receiving systems. Filters are one of the major components that have a quality to select the frequency required [1-2]. The demand for wideband wireless communication has been increasing rapidly. This is due to the need to support more users and to provide more information with a higher data rate [3].

The applications of WiMAX (Worldwide Interoperability for Microwave Access) are very popular with lots of advantages, to provide communication services at anytime and anywhere for the users. The coverage of WiMAX is up to $50 \mathrm{~km}$ radius and the allocated bands for this application are: Low band (2.5$2.69 \mathrm{GHz})$, Middle band (3.2-3.8 GHz) and Upper band $(5.25-8 \mathrm{GHz})$. [4]. In the recent years to design a multiband antenna has become an important issue in wireless area. Antenna is a type of transducer which is used to convert electrical energy into RF energy. Antenna is a basic device for any communication setup. Now multiband antenna is the second important issue for designing any antenna. In simple terms a multiband antenna is a device which can operate multiple frequencies. [5]

Generally, metamaterials are some sort of artificial structures which will exhibit unusual electromagnetic properties. The history of metamaterials started in the year of 1968 where it was introduced by a man named V. G. Veselago. This artificial structure can exhibit negative permittivity, negative permeability and a negative refractive index that could not be found in nature. [1-2][56] After 30 years, in the year of 1999, Professor J. B. Pendry have proposed a thin-wire design and the split ring resonator, which exhibit negative permittivity and negative permeability value respectively. [1][7-8] Both of the structures was then been combined by Doctor A. Smith and became the first metamaterial that was fabricated. Later then in the year of 2004, Falcone et al. introduced Complimentary Split Ring Resonator (CSRR) as resonant elements that can also generate negative permittivity. [6] There are many advantages of using CSRR, such ' as compact in size, low cost and low radiation loss. [9] All of these features are very useful especially for the wireless communication system. [10].

In this paper, the design of dual-band metamaterial filtenna is proposed. Dual-band metamaterial filtenna is basically, a combination of a metamaterial band-stop filter and a wideband antenna. A wideband antenna is filtered by using a metamaterial band-stop filter. As known, the bandstop filter will reject the frequency at the particular frequency that has been set. The band-stop filter is set to operate at the frequency of $4.65 \mathrm{GHz}$. The CSRR is 
implemented at the ground plane of the wideband antenna. The optimized design of the filtenna will operate at 2.6 $\mathrm{GHz}$ and $5.2 \mathrm{GHz}$.

\section{FILTENNA DESIGN}

The followings section explain the design specifications of the metamaterial band-stop filter, the wideband antenna and the dual-band metamaterial filtenna. All of the designs are constructed on a FR4 substrate with the relative permittivity of 4.3 and thickness of $1.6 \mathrm{~mm}$.

\subsection{Metamaterial Band-stop Filter}

The design of metamaterial band-stop filter has been inspired from [2] but the design of the filter has been changed and altered in order to make it as a band-stop filter. Figure 1 shows the design of a unit cell of the metamaterial band-stop filter.

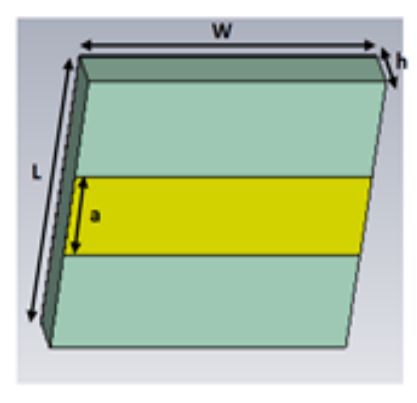

(a)

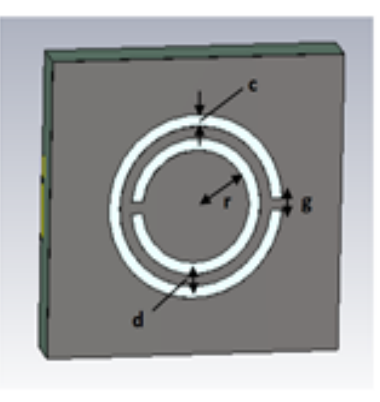

(b)
Figure 1. Design of a unit cell of the metamaterial bandstop filter. (a) front view (b) back view

The design specification of the above unit cell of the metamaterial band-stop filter is shown in Table 1.

Table 1. Dimensions of the unit cell of the metamaterial band-stop filter design.

\begin{tabular}{|c|c|}
\hline Parameters & Optimized Value (mm) \\
\hline L & 10 \\
\hline W & 10.73 \\
\hline $\mathrm{a}$ & 2.91 \\
\hline $\mathrm{h}$ & 1.6 \\
\hline $\mathrm{r}$ & 2.78 \\
\hline $\mathrm{c}$ & 0.4 \\
\hline $\mathrm{d}$ & 0.4 \\
\hline $\mathrm{g}$ & 0.4 \\
\hline
\end{tabular}

In order to improve the band-stop filter performances, three-unit cell has been implemented as shown in Figure 2.

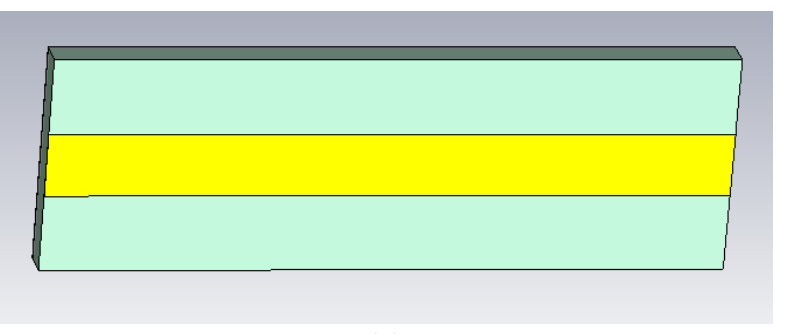

(a)

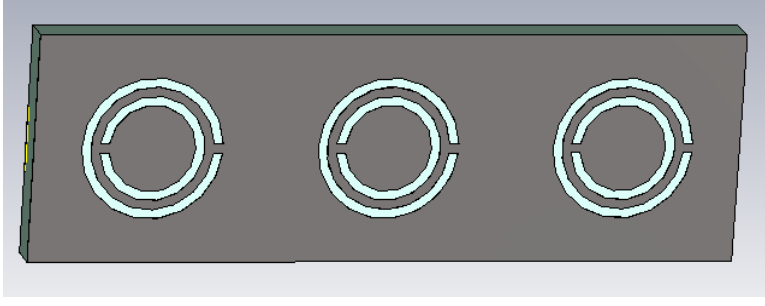

(b)

Figure 2. Design of the metamaterial band-stop filter. (a) front view (b) back view

\subsection{Wideband Antenna}

The design of wideband antenna has been inspired from [11] as shown in Figure 3 but the design of the antenna has been altered to achieve the optimization for this project. The wideband antenna is operate at multiband frequency from $2 \mathrm{GHz}$ to $7 \mathrm{GHz}$.

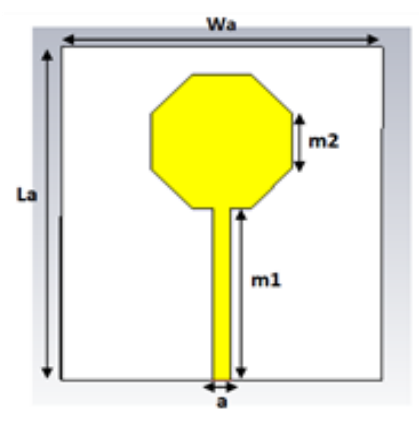

(a)

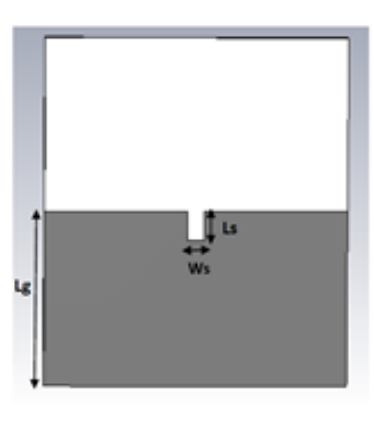

(b)
Figure 3. Design of the wideband antenna. (a) front view (b) back view

The design specification of the above wideband antenna design is shown in the Table 2.

Table 2. Dimensions of the wideband antenna design

\begin{tabular}{|c|c|}
\hline Parameters & Optimized Value (mm) \\
\hline $\mathrm{La}$ & 60 \\
\hline $\mathrm{Wa}$ & 55 \\
\hline $\mathrm{a}$ & 2.91 \\
\hline $\mathrm{m} 1$ & 31.11 \\
\hline $\mathrm{m} 2$ & 10 \\
\hline $\mathrm{Lg}$ & 30.11 \\
\hline $\mathrm{Ls}$ & 5 \\
\hline $\mathrm{Ws}$ & 3 \\
\hline
\end{tabular}




\subsection{Dual-band Metamaterial Filtenna}

The design of dual-band metamaterial filtenna is basically the combination of the metamaterial band-stop filter and the wideband antenna as shown in Figure 4. One of the advantages of having both designs in one structure is compact size.

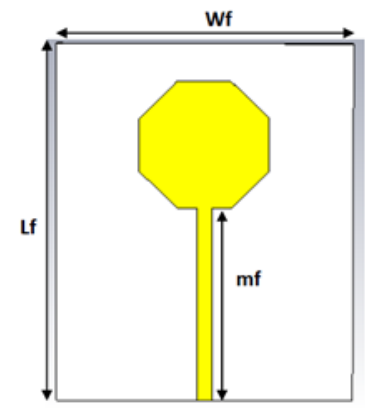

(a)

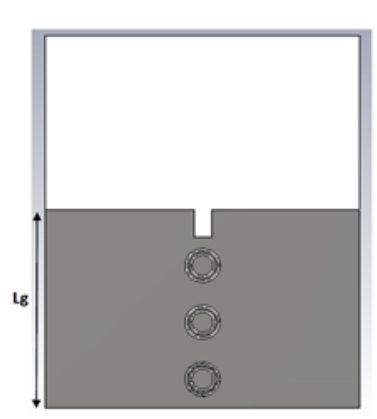

(b)
Figure 4. Design of the dual band metamaterial filtenna. (a) front view (b) back view

The design specification of the above dual-band metamaterial filtenna design is shown in Table 3 . The overall size of the filtenna is same with the wideband antenna although it combine with band-stop filter.

Table 3. Dimensions of the dual-band metamaterial filtenna design

\begin{tabular}{|c|c|}
\hline Parameters & Optimized Value (mm) \\
\hline Lf & 60 \\
\hline Wf & 55 \\
\hline $\mathrm{mf}$ & 31.11 \\
\hline $\mathrm{Lg}$ & 30.11 \\
\hline
\end{tabular}

\section{SIMULATION RESULTS AND DISCUSSION}

All the designed is simulated using the CST Studio software and the simulation the results are shown in the following section.

\subsection{Metamaterial Band-stop Filter}

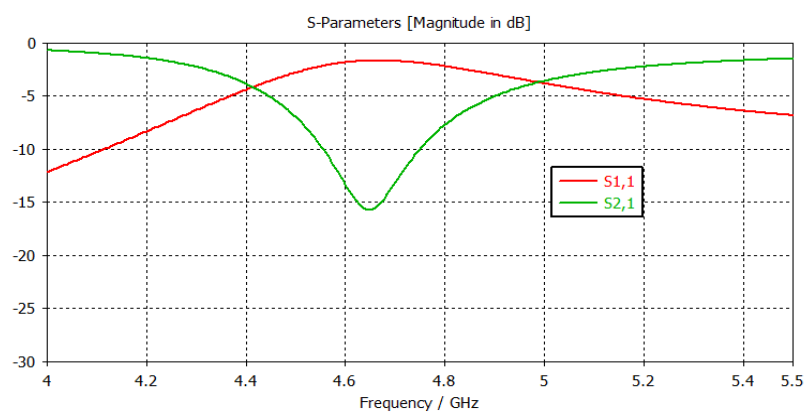

Figure 5. S11 and S21 parameters of a unit cell of the metamaterial band-stop filter
Figure 5 depicts the $\mathrm{S}$-parameters output response of a unit cell of the metamaterial band-stop filter. It shows that the metamaterial band-stop filter operates at $4.65 \mathrm{GHz}$. Furthermore, it also shows that the return loss, S11 of the filter is $-1.7 \mathrm{~dB}$ and the insertion loss, $\mathrm{S} 21$ of the filter is $15.72 \mathrm{~dB}$. The bandwidth for this filter is $13.76 \%$.

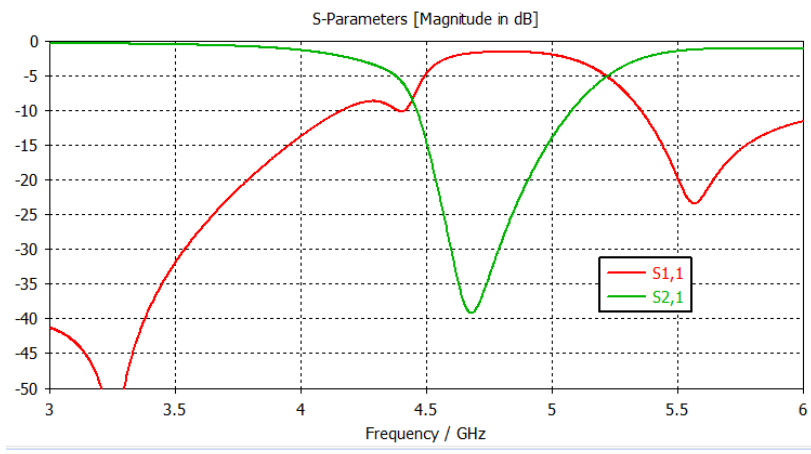

Figure 5. $S_{11}$ and $S_{21}$ parameters of three-unit cell of the metamaterial band-stop filter

Figure 6 shows the S-parameter response of three-unit cell of the metamaterial band-stop filter. It can be seen that the band-stop filter operates well at $4.65 \mathrm{GHz}$. It is noticed that the performance of the band-stop filter has been improved compared to the previous performance of the single unit cell. The insertion loss of the filter is obtained as $-39 \mathrm{~dB}$ and the $3 \mathrm{~dB}$ filter bandwidth is calculated as $22.58 \%$. Therefore, the objective of designing a metamaterial band-stop filter that operates at the frequency of $4 \mathrm{GHz}$ has been achieved. The signal is being filtered by the filter at the operating frequency which means that there is no signal being transmitted.

\subsection{Dual-band Metamaterial Filtenna}

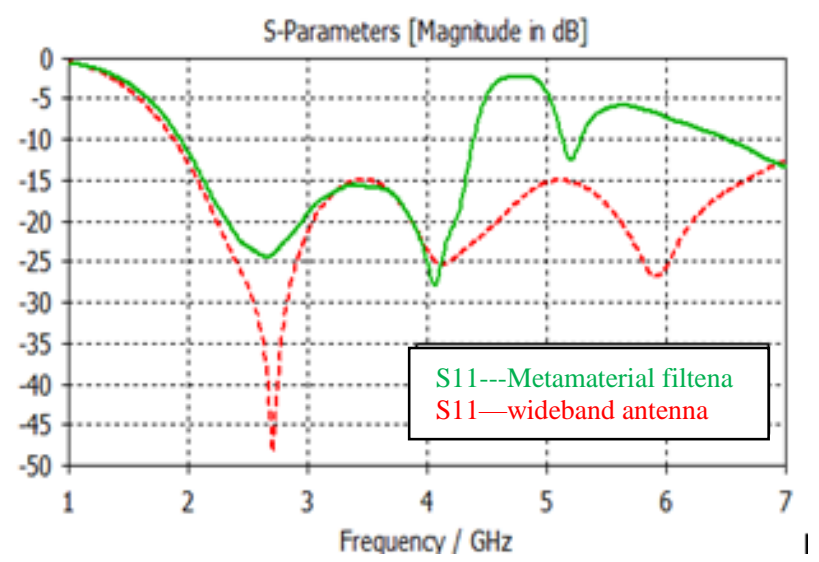

Figure 6. $\mathrm{S}_{11}$ parameter of the wideband antenna and metamaterial filtenna

Figure 7 shows the S-parameter response of the wideband antenna. From the output response, it shows that the range of frequency that is below $-10 \mathrm{~dB}$ return loss is from $1 \mathrm{GHz}$ to $7 \mathrm{GHz}$. Therefore, based on the operating frequencies of the antenna, the antenna can be considered as a wideband antenna. Besides that, figure 7 shows the Sparameter response of the dual-band metamaterial filtenna. 
From the output response, it shows that the filtenna operates at the operating frequency of $2.6 \mathrm{GHz}$ and 5.2 $\mathrm{GHz}$ with the bandwidth $2.4 \mathrm{GHz}$ and $0.2 \mathrm{GHz}$ respectively. Other than that, at the range of frequency of 4.4-5.1 GHz, the signal is being filtered by the filtenna and the signal is not transmitted at this frequency. Therefore, the filtenna operates at dual-band of frequency. Furthermore, from the operating frequencies of the filtenna, it shows that the filtenna can cover the range of frequency for WiMAX application.

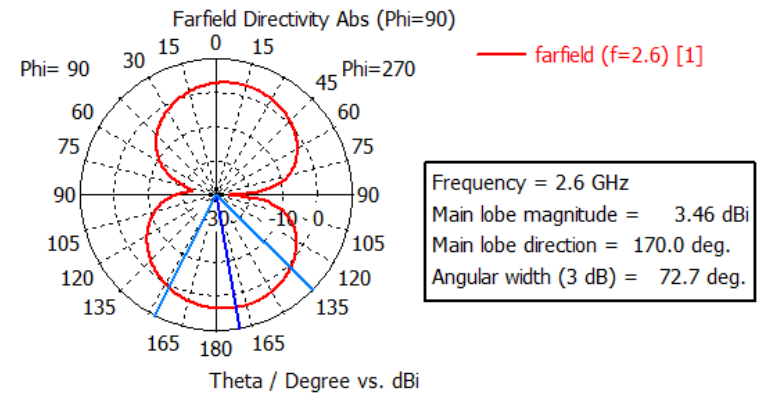

Figure 8. Radiation pattern of the dual-band metamaterial filtenna at $2.6 \mathrm{GHz}$

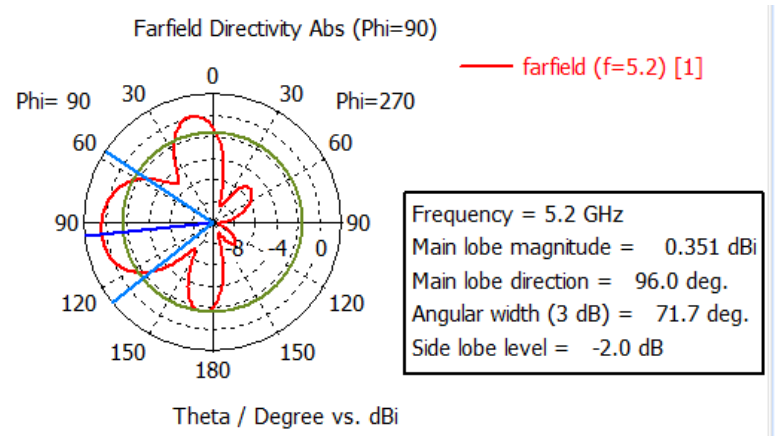

Figure 9. Radiation pattern of the dual-band metamaterial filtenna at $5.2 \mathrm{GHz}$

Figure 8 shows the radiation pattern of the dual-band metamaterial filtenna at frequency $3.6 \mathrm{GHz}$ with the gain is $3.46 \mathrm{dBi}$. While, in Figure 9 shows the radiation pattern of the dual-band metamaterial filtenna at frequency 5.2 $\mathrm{GHz}$ with the gain is $0.351 \mathrm{dBi}$.

\section{CONCLUSION}

As a conclusion, the dual-band metamaterial filtenna has been designed by combining the metamaterial band-stop filter and the wideband antenna in one structure. By combining both of the components in one structure, the size of the communication devices can be design more compact and it also can reduce some amount of transmission losses. In addition, the filtenna design has achieved the specification target of this project. The filtenna operates at dual-band frequency of $2.6 \mathrm{GHz}$ and
5.2 GHz. Based on the operating frequencies, it can be used for WiMAX wireless application.

\section{ACKNOWLEDGMENT}

The authors would like to thank the Ministry of Higher Education (MOHE), Research Management Centre (RMC), School of Electrical Engineering, Universiti Teknologi Malaysia (UTM) for supporting the research work, under grant no. 14J22.

\section{REFERENCES}

[1] B. Nasiri, A. Errkik, J. Zbitou, A. Tajmouati, L. Elabdellaoui, and M. Latrach, "A novel design of a compact miniature microstrip low pass filter based on SRR," 2017 Int. Conf. Wirel. Technol. Embed. Intell. Syst., pp. 1-5, 2017.

[2] S. S. Laharia, A. Laharia, and P. S. Tomar, "Design and Analysis of Microstrip Low Pass Filter Using Metamaterial Structures and Host Transmission Line," 2016 8th Int. Conf. Comput. Intell. Commun. Networks, pp. 183-186, 2016.

[3] Z. Jiang, X. Lu, B. Zhang, W. Sun, and Y. Zhong, "Design of a Miniaturized Ultra-wideband Antenna with U-shape Slots," vol. 230009, no. 1, pp. 1-2.

[4] V. G. Ajay and T. Mathew, "Size Reduction of Microstrip Patch Antenna Through Metamaterial Approach for WiMAX Application,” pp. 379-381, 2017.

[5] B. P. Kumawat, S. Meena, and S. Yadav, "Square Shape Slotted Multiband Microstrip Patch Antenna Using Defect Ground Structure," no. 1, pp. 3-6.

[6] I. Zagoya-mellado and A. Corona-chavez, "Miniaturized Metamaterial Filters Using Ring Resonators," no. 1, pp. 45-48, 2009.

[7] H. Nasraoui, A. Mouhsen, J. El Aoufi, and M. Taouzari, "Novel Microstrip low pass Filter Based on Complementary Split-Ring resonators," no. 10, pp. 8-11, 2014.

[8] N. M. Devi and S. Maity, "Metamaterial-based miniaturized CPW band stop filter design on silicon substrate for microwave applications," 2014 Int. Conf. Control. Instrumentation, Commun. Comput. Technol. ICCICCT 2014, pp. 171-174, 2014.

[9] M. Duran-Sindreu, P. Velez, J. Bonache, and F. Martin, "Broadband microwave filters based on metamaterial concepts," 2010 Conf. Proc. ICECom, 20th Int. Conf. Appl. Electromagn. Commun., pp. 14, 2010.

[10] J. C. Liu, H. C. Lin, B. H. Zeng, K. D. Yeh, and D. C. Chang, "An improved equivalent circuit model for csrr-based bandpass filter design with even and odd modes," IEEE Microw. Wirel. Components Lett., vol. 20, no. 4, pp. 193-195, 2010.

[11] R. K. Saraswat, A. K. Chaturvedi, V. Sharma, and Jagmohan, "Slotted Ground Miniaturized UWB Antenna Metamaterial Inspired for WLAN and WiMAX Applications," Proc. - 2016 8th Int. Conf. Comput. Intell. Commun. Networks, CICN 2016, vol. i, pp. 213-216, 2017. 